treatise in which $I$ can find any thing like a due recognition of the value of this medicine is in Phillips" "Materia Medica and Therapeutics," 1882, where he refers to several cases in which it was successful, having previously spoken of the disease as one that "has usually ended fatally by exhaustion and collapse in spite of iron, food," \&c. Such, then, being the general view taken by the profession with regard to the fatality of the malady and the uselessness of treatment, as reflected in our best literature, it is time, I think, that those who, like myself, may in the course of their practice be brought into contact with it, and may seek, and seek in vain, for counsel to guide them in the pages of our most recent and approved authorities, should have placed prominently before them the only treatment as yet attended by a fair degree of success, and their despair converted into a reasonable amount of hope. That such hope would not be unfounded will, I believe, be seen from the data I have brought forward, and from the following summary which I lave drawn up from such data, and which, I think, would justify us in saying that the "name given to the disease by Biermer" does now "cease to be applicable."

Of forty-eight cases treated without arsenic, or treatment not recorded, forty-two were fatal, two under treatment (getting worse), three result not known, one recovered (elearly a case of leukrmia); authorities-Hobson, Coupland, Mackenzie, Bramwell, and Barclay. Of twenty-two cases treated by arsenic, sixteen recovered, two improved, and four proved fatal; authorities-Hobson, Coupland, Bramwell, Finny, Broadbent, Withers-Moore, Lockie, and Padley. In the whole list there is not, with one exception, a single authentic case of recovery in which arsenic did not form a chief part of the treatment; and in the exceptional case arsenic was first given and carbonate of iron followed. As Dr. Hobson's collection evidently includes most of the cases given in Dr. Taylor's paper, and probably some in Dr. Pye. Smith's résumé, as well as some cases published by Dr. Wilks in Guy's Hospital Reports, I have excluded these. It is also possible that there may be some other cases of repetition from a similar cause, but this would not affect the general conclusion. I may here refer to a case reported 8 as one of "pernicious anæmia," in which recovery took place after the administration of a pill containing morphia, creasote, and nux vomica, followed by citrate of iron and quinine and cod-liver oil. There is nothing, however, by which to identify this case as one of the disease in question, and the description generally does not accord with our conception of it. It was thought to be a case of malignant disease until a gain of sixteen pounds in fourteen days followed by recovery disproved this idea. A simple anæmic state dependent on some gastric disorder would, I think, have been the more correct diagnosis in this case.

I did not intend in this paper to touch upon any pathological question, but I could not help being struck with the marked discrepancy existing between the influence upon the blood of arsenic when taken in a state of health, or its physiological action, and when administered in the disease under consideration, its therapentical action. I mean the diminution of the red blood-corpuscles in the former case, and their increase, as well as improvement, in the latter. Thus Phillips quotes the case of a gentleman suffering from cerebral congestion, the result of plethora, who was relieved by arsenical treatment, which materially reduced the amount of blood-clot and the number of corpuscles; and he adduces other instances. This, among other things, would seem to point to the primary influence of the medicine being exercised upon the ganglionic nervous system, in favour of which there is certainly much to be said.

The chief practical conclusions to be drawn from what has been here advanced are :-That in arsenic we have a medicine exercising what may almost be termed a specific action in "idiopathic anæmia " that in a clearly recognised case it is useless, and worse than useless, pouring in iron, and, unless as auxiliaries, other tonics; that arsenic appears to act best in its simple and uncombined form, and that its action is rather interfered with than otherwise by combination with iron; that the failure of iron-so potent in other forms of anæmia-serves as a kind of therapeutic diagnostic between these and idiopathic anæmia; and that the prognosis and directions for treatment of our chief authorities on medicine and therapeutics are, I say it with all deference, misleading and unduly discouraging, inasmuch as they are either altogether silent upon, or enumerate cursorily with other medicines, the only agent which appears to have exercised a real and essential influence upon the disease, and which has undrubtedly been the means of rescuing a large proportion of sufferers from its otherwise deadly power.

As an addendum to this paper, written in June last, I may state that I have since heard twice from my patientthe last time about ten days ago, that is about seven months from the time of my first seeing him, - aud that he has con. tinued to progress favourably in all respects.

Swansea.

\section{A MEDICO-LEGAL MYSTERY.}

BY W. WYNN WESTCOTT, M.B. LoND., DEPUTY CORONER FOR CENTRAL MIDDLESEX;

AND

SAMUEL LLOYD,

SURGEON, E DIVISION OF POLICE.

THE following notes of a mysterious death are offered to the profession because they show the peculiar difficulties which are often encountered in trying to solve the problem of how death has been caused, and also at what time it occurred. Our only regret is that we are unable to fix in this case either the cause of the injuries found at the post-mortem examination, or the time at which death took place. The deceased was a married woman, aged sixtyone years, living alone with her husband, who was a tailor. Both were addicted to intemperance; the husband was of courteous demeanour to his wife when they were both sober, but when intoxicated had differences at times, as is usual in such cases. From the evidence offered at the coroner's inquest before Dr. Wynn Westcott, we abstract the following particulars. Both husband and wife were in their usual health during a certain Sunday, but in the evening they were both the worse for liquor. During the Sunday night the next door neighbour heard snatches of drunken singing, commencing about midnight, and she states that she recognised the voice of the husband singing at short intervals up to $5 \mathrm{~A}$ M. on Monday morning, she being restless during the night, and disturbed by the singing. She heard no quarrelling, nor cries of suffering. We should state that the ground-floor front room was used as the tailor's shop, and the remainder of the house was the dwelling of the deceased and her husband. It is an oldfasbioned house, with a small enclosed yard behind, and the staircases arranged in short flights of about nine steps, the outer edge of each flush with the next above, so that it is almost impossible for a person on the first floor to fall on to the ground floor, and quite impossible to see the ground floor from the first-floor landing. The adjacent house on one side is at present empty; that on the other side was the home of the neighbour who overheard the singing. About 9 A.M. on the Monday morning, the son-in-law, who was in partnership with the husband of the deceased woman, and who lived with his wife at a distance from his place of business, arrived as usual at the house of the deceased, and noticed with surprise that the blinds of the shop window were still in their Sunday condition, closed. Having a latchkey, and finding the door not bolted, he entered, and perceived the door at the further end of the passage leading into the courtyard open. Midway in the passage, where there are two steps near the foot of the first-floor staircase, he saw his mother-in-law lying apparently dead or insensible, and, noticing two small pools of blood between him and her, he retreated to the street and called in a neighbour who happened to be at her door. She then joined him in looking at the body, and, judging her to be dead, they both left, and he closed the street door and went for a medical man. Mr. Lloyd and his assistant returned with the son-inlaw and entered the passage.

The deceased was found to be quite dead and cold, and the rigor mortis perfectly developed. She was dressed in every-day costume, lying with her buttocks on a mat at the foot of the two stairs, reclining against them on her right side, her back to the wall. It was then noticed that although the back of her head just touched the wall, it was not supported by anything, and had not dropped upon her right shoulder. A rectangular wound was found on the scalp near the occipital protuberance; this was still wet with 
blood, and there was a mark of blood on the wall where the head was resting. Between the front door and the body and about one or two feet from it were two small pools of clotted blood. Neither the hands nor the shnes of the deceased were bloody, and there were no bloody footmarks, nor any blood on any other part of deceased, nor on her clothes. There were no other marks of violence visible, nor any signs of a struggle whatever. Beneath the body was found an old pewter tall candlestick; this had no recent crack or injury, nor blood-stain. Near the pools of blood was a candle, which had been lighted at some time; it was crushed by pressure, and adhering to it was a coil of twine. I' was adberent to the floor and was discoloured, perhaps by blood. No weapon and nothing else unusual was found on the ground floor. Upstairs it was found that the bedroom was undisturbed, the bed had not been slept in. On enter. ing the front downstairs room the husband was found lying on a sofa apparently insensible from drink. Bottles and glasses containing small quantities of beer and rum were on the table. The windows were not curtained nor were the shutters closed, nor was the gas alight. Everything appeared as if the room had not been lighted up the previous evening. There were no signs of any struggle having occurred, and no marks of blood on anything, except that on the mantelpiece was a clay pipe which bore stains of bloody fingers. In the back kitchen sink were two small vessels containing fluid : in one (a small tureen) the liquid was pink, and was found to be stained with blood. The husbaud, who was dressed in every.day clothes, was aroused and told of his wife's death. He only answered, "I know nothing about it." Blood-stains were found on his hands and on his face, which bore marks of scratches and some shaving scars ; here were blood-stains also on his waistcoat and on the front of his trousers, on one stocking, and on one shirtsleeve, but the coat was clean, and the inside of the coatsleeve corresponding to the stained shirt-sleeve was clean. His clothing was not torn, and there were no marks of any struggte having taken place. The inspector of police $n \in X$ arrived, and to him the husband stated, after being cautioned, that " he had gone to pick her up; she had asked him for some brandy; he had gone down to fetch it, but had fallen asleep and forgotten all about it." The husband, however, was still partially insensible from drink throughout the moraing. He was arrested and charged with causing the death, aud remanded until the verdict of the coroner's jury had been given. The effect of which proceeding was of course to prevent his giving any evidence at the inquest. On an examination of his clothing it was found that the blood-stain of the trousers- bore evidence of an attempt having been made to wash out the stains, but this was not the case with the other stains on the clothes.

At a post-mortem examination of the body, made by Mr. Lloyd, twenty-six hours after the discovery of the body, the following notes were taken :-Age about sixty, body well nourished, weight about twelve stone; no external mariss of violence except the wound of the scalp before mentioned, which was of rectangular shape, its two sides about one-third of an inch long each; it was situated just above the oceipital protuberance, it did not extend down to the bone. There was some bruising of the scalp around it, but no fracture of the skull, and the brain was found to be quite healthy and free from injury. The lungs were congested and emphysematous; there were some old adhesions on the right side. The diaphragm was ruptured, and the greater part of the stomach and the spleen had passed through the rent into the left pleural cavity. The ribs, from the third to the ninth on the left side, were all broken, the fractures forming an even line extending down wards and outwards from about one inch external to the junction of the third rib, with its costal cartilage. The broken ends of the ribs had not punctured the pleura, but there was extravasation of blood around them. The heart exhibited concentric hypertrophy of the left ventricle; there were atheromatous patches on the intima. The lining membrane of the stomach was reddened, the liver cirrhosed, the kidneys more vascular than usual, their capsules adherent, and their surface nodular.

In answer to questions put by the coroner the medical witness stated that the effects of such terrible injuries to the diaphragm and displacement of the viscera must have been to cause sudden death, possibly without any andible cry; that the injury must have been caused by a sudden violent compression of the body against a resisting even edge, such as the edge of a stair or a banister rail, or else by an excessively violent blow by a long blunt weapon. Further, that the scalp wound was not sufficient to cause the death although it might account for all the blood found. He did not consider the scalp wound had been caused by the candlestick produced, because it was uninjured and clean, and because it was of too brittle a metal not to show signs of violence. And, finally, considering the formation of the staircases precluding the idea of a fall from a height, and in the absence of any weapon, he was unable to assign any probable cause of the injuries. Being questioned as to the time at which death occurred, he stated that it was almost im. possible to guess, from the fact that the body was in a sense absolutely cold and the cadaveric rigidity perfect; the deceased must have been dead for some hours before 9 A.M. on Monday. She might have been dead since sunset on Sunday evening. He considered, however, that it was certain that the body had been moved since the rigor mortis had set in, because when found the stiffened neck was supporting the head; this appearance could not have existed if the person had died in the situation where she was found. Hence he concluded that some person, probably the blood-stained husband, had moved the body some hours after death from the position in which she had died and stiffened to where the body was found. 'The coroner's jury having been assured that no further evidence was likely to be fortheoming unavoidably returned a verdict of "Death from injuries described by the medical witness, but how these had been caused there was no evidence to show." The magistrate having heard the verdict of the coroner's jury, dismissed the husband from custody immediately, and so rests at present this mysterious case.

We cannot but think that if such cases as this one were more often reported in the medical journals much light might be thrown on the undecided questions of how soon after death the rigor mortis comes on, and how long it may last, taking into consideration the mode of deatb, the bodily bealth of the deceased, the presence or absence of intoxica. tion, and a vast number of other important medico.legal conditions, and we hope that the publication of this case may lead medical coroners and witnesses to accumulate a body of evidence which will enable medical jurists to cast a clear light on many such disputed topics.

\section{ON PTOMAINES, OR CADAVERIC ALKALOIDS.}

\section{By R. N. WOLFENDEN, B.A., M.B.CANTAB., F.C.S., LECTURER ON PHYSTOLOGY IN THE CHARING-CROSS HOSPITAL} MEDICAL SCHOOL.

Arong the many decompositions of proteids none are of more interest than that series of changes that give rise to the production of ptomaines, or cadaveric alkaloids. Whether regarded from a forensic point of view, or as pathological plenomena, they are of surpassing interest. A recent trial for murder brought the name of "ptomaine" into prominence, and the counsel who made use of the facts already known only to specialists for their defence undoubtedly exhilited much cleverness. Considering the importance of the subject in pathological chemistry, and the little that is known about it, except to those of us who have worked more or less in this direction, I shall endeavour to give a short résumé of the facts already pus before the scientific public.

Though the term " ptomaine" was first applied by Selmi to these bodies to indicate that they were of cadaveric origin, their distribution is no longer to be limited to the cadaver, but investigations are rendering it more and more probable that alkaloids of a poisonous nature occur in certain pathological conditions, and possibly also normally, as a product of change of living tissue. Selmi's first observations were made on corpses dead of arsenical poisoning, and it is of interest to refer to his methods. The liquid under observation was made alkaline with baryta water, and then extracted with ether; acicular crystals were produced, which precipitated the principal reagents that alkaloids answer to, with the exception of platinum chloride. Selmi's second attempt was made by extracting the liquid with aqueons alcohol, then making alkaline with baryta, shaking with ether, ridding of the ether by spontaneous evaporation and distillation, treating the turbid liquid thus left by wateracidulated with acetic acid, filtering and evaporating to dryness; then taking up the residue with water, again rendering alka. 